\title{
A Study on the Usage of Smartphones amongst First Year Medical Students in an Indian Medical College
}

\author{
Authors \\ Dr Perumallapalli Haresh Kumar ${ }^{1}$, Dr Mythili Krishnan ${ }^{2}$, Capt Samrat Sapkota ${ }^{2}$ \\ ${ }^{1}$ Associate Professor, Department of Anatomy, Armed Forces Medical College, Pune \\ ${ }^{2}$ Resident, Department of Anatomy, Armed Forces Medical College, Pune
}

\begin{abstract}
Advancements in technology have always had major impacts in medicine. The advent of the smart phone has been one of the latest technologies to penetrate all over the world and has been adapted to the medical field. The Student community has always been the fastest to adapt to changing technologies. Smartphones has revolutionized communication and has simplified access to email, performing Internet searches, and using specific applications. The smartphone is one of the fastest growing sectors in the technology industry, and its impact in medicine has already been significant.

Objective:To examine the changing trend of smartphone usage amongst first year students over a period of one year.

Methods: A survey was conducted at the beginning of the medical school and after one year to evaluate the trends of smartphone usage amongst students.

Keywords: Smartphone, technology, education, medicine.
\end{abstract}

\section{Introduction}

Advancements in technology have always had major impacts in medicine. The smart phone has been one of the latest technologies to penetrate all over the world and has been adapted to the medical field. The Student community has always been the fastest to adapt to changing technologies. Smartphones has revolutionized communication, simplified access to email, performing Internet searches, and using specific applications. The role of Smartphones in medical education is fast being recognized since they are portable, omnipresent and user friendly. Students can be easily motivated and encouraged to use smartphones as self-study devices and also for reference. The development of medical related apps has shown a dramatic increase especially with the growing popularity of the android platform.

\section{Objective}

To examine the changing trend of smartphone usage amongst first year students over a period of one year in a leading medical college in India.

\section{Methods}

All the medical students of first year (I Term) were included in the study and a questionnaire was distributed to them at the beginning of their preclinical course. The responses were recorded. The same group of students was surveyed after one year when they were undergoing clinical postings (IIIrd Term) along with Para clinical 
subjects with the same questionnaire and data was collected. The data was analyzed with the help of appropriate software to study the penetration, functional usage and acceptability by the students.

\section{Results}

A total of 131 students were enrolled in the study. All students owned a cell phone however only 91
(69.4\%) students owned Smartphones at the beginning of the study. There was an increase of smartphone ownership during the study to reach $108(83 \%)$ by the end of the first year. Medical Apps ownership was polled and found to have increased during the study period from $76 \%$ to $85 \%$ (table 1). Not only ownership but increase in the number of apps was seen during the study.

\section{Percentage of medical students owning medical related smartphone apps}

$\begin{array}{lll}\text { Question response } & \text { I term }(\mathrm{n}=91) & \text { III term }(\mathrm{n}=108) \\ \text { No } & 22(24.17 \%) & 16(14.81 \%) \\ \text { Yes }-1-5 \text { apps } & 63(69.23 \%) & 68(62.96 \%) \\ \text { Yes }-6-10 \text { apps } & 4(4.39 \%) & 17(15.74 \%) \\ \text { Yes }-11-15 \text { apps } & 0(0 \%) & 3(2.77 \%) \\ \text { Yes }-16-20 \text { apps } & 1(1.09 \%) & 3(2.77 \%) \\ \text { Yes }-21-25 \text { apps } & 0(0 \%) & 0(0 \%) \\ \text { Yes }-26-30 \text { apps } & 0(0 \%) & 0(0 \%) \\ \text { Yes }-31+\text { apps } & 1(1.09 \%) & 1(0.92 \%)\end{array}$

(Table 1)

\section{Analysis \& Discussion}

\section{Term students}

131 medical students were surveyed at the beginning their first year curriculum. The male to

female ratio was 79: 21 (103 \& 28 respectively, $\mathrm{n}=131$ )

$\begin{array}{lllll}\text { Smart phone } & \begin{array}{l}\text { No. of students } \\ (\mathrm{n}=91)\end{array} & \text { using } & \text { Percentage(\%) } & \begin{array}{l}\text { Percentage(\%) } \\ \text { Among 69 }\end{array} \\ \text { iPhone } & 7 & 7.69 & 7.25 \\ \text { Android } & 54 & 59.34 & 66.67 \\ \text { Others } & 30 & 32.96 & 26.09 \\ \text { Not having } & 40 & & \end{array}$

(Table 2)

Among the smartphones used by students, Google android accounts for around two thirds of the amount i.e $66 \%$ out of smartphone users. iPhone was owned by $8 \%$ and the rest $26 \%$ of the students were having 'other' smartphones.

Out of the 91 smartphone users, 69 (76\%) students were having medical apps on their devices. Among 69 smartphone users who were having medical apps, $67 \%$ are having android platform, $26 \%$ were using other smartphones and mere $7 \%$ were iPhone users.
Basic utility of medical apps among students is for learning (81) as compared to revision (68). Out of 131 students participated in the study, $70 \%$ (92) of the students were keen to use the smartphone app specific to medical school.

Frequency of use of medical related apps within medical students

As seen in table 2 almost half (51\%) 46 students admitted to using their smartphones at least once a day, this can be relevant in a teaching setting. 


\begin{tabular}{|c|c|c|c|c|c|}
\hline Question response & $\begin{array}{l}\text { I Term } \\
\mathrm{n}=69\end{array}$ & $\%$ & & $\begin{array}{l}\text { III Term } \\
n=92\end{array}$ & $\%$ \\
\hline Several times a day & 8 & 11.59 & 20 & & 21.74 \\
\hline Once or twice a day & 27 & 39.13 & & 25 & 27.17 \\
\hline 2-3 times a week & 19 & 27.54 & & 27 & 29.35 \\
\hline Once a week & 7 & 10.14 & & 8 & 8.70 \\
\hline Rarely used & 5 & 7.25 & & 11 & 11.96 \\
\hline Never used & 3 & 4.35 & & 1 & 1.09 \\
\hline
\end{tabular}

\section{Use of smartphones in minutes per day}

The average time students used their smart phones for reference and study was $30 \mathrm{~min}(70 \%)$ (Table

$\begin{array}{ll}\begin{array}{l}\text { Question } \\ \text { response }\end{array} & \text { I Term } \\ \text { None } & \text { 3 } \\ \text { 1-10 minutes } & 20 \\ 11-20 \text { minutes } & 15 \\ \text { 21-30 minutes } & 15 \\ \text { 31-40 minutes } & 7 \\ \text { 41+ minutes } & 9\end{array}$

(Table 4)

\section{III rd Term}

The same questionnaires were given to the same set of students after passing their preclinical subjects. At this stage, the students had clinical postings along with their Para clinical subjects.

Out of 131 students got involved in the study, 82 $\%$ (108/ 131) were having smartphones. The
4) This fact will enable software writers to make apps with a short duration span to maximize usage.

\section{Term}

$\%$
4.35
28.99
21.74
21.74
10.14
13.04

$\mathrm{n}$
7
46
24
8
6
1

$\%$

7.61

50.00

26.09

8.70

6.52

1.09

preferred operating system being Google Android with $70 \%$. Among the rest, $22 \%$ were using 'other' smartphones. iPhone took the last place with $7 \%$. The tally of students using iPhone remained same across the period. But the trend to attract new users towards Android was clearly visible.

$\begin{array}{lll}\text { Smart phone } & \text { No. of students using }(\mathrm{n}=108) & \text { Percentage }(\%) \\ \text { iPhone } & 8 & 7.4 \\ \text { Android } & 76 & 70.37 \\ \text { Others } & 24 & 22.22 \\ \text { Not having } & 23 & \end{array}$

(Table 5)

The percentage of males having smartphones as well as apps in smartphone was higher than that of female students. The percentage of iPhone users having apps was higher than android and 'other' smartphone users.The students were utilizing medical apps mainly for learning rather than for clinical purpose. Among learning, 63\% were using apps for learning as compared to $38 \%$ for revising. The equation of app users in clinical set up was $16 \%$ in ward environment to $25 \%$ in clinic environment. 


\section{Review of Literature \& Discussion}

Garritty et al. in a study among healthcare providers showed that $45 \%$ to $85 \%$ usea PDA with younger physicians or residents more likely to use them ${ }^{(1)}$. Dasari et al. who questioned British anesthetistsfound that $59 \%$ owned an iPhone. Also $80 \%$ of those owning an iPhone actively used medical apps, with $60 \%$ using them for clinical activities and $47 \%$ for educational activities ${ }^{(2)}$. Grasso et al.reported 52\% of US medical students using handheld computers, but there was a clear difference between pre- clinical and clinical years (28\% and $76 \%$ respectively) ${ }^{(3)}$.A study conducted by Payne et al in 2012 (4) in UK showed smartphone ownership within pre-clinical and clinical years (76\% and $80 \%$ respectively), and app usage as high as $83.3 \%$ (for educational purposes). Our study has shown smartphone ownwership at $76 \%$ increasing to $86 \%$ within one year. This matches the prevalence of medical students in the UK.

Within the student group, It is noticed that educational use of apps starts in pre-clinical yearsand also follow into clinical years, with both year groups using apps more for educational than clinical purposes. It is noticed that there was no pattern relating to frequency and time spent while using apps specific to clinical and educational environment ${ }^{(4)}$. Daily use of Majority of students was between 1 and 20 minutes, with a very few longer than 30 minutes(Table 3). Regarding number and type of medical apps used or owned it was seen that students are use one to five apps only on a regular basis. Similar to previous studies (4) the most frequently used apps were those detailing drug reference and free apps involved with disease diagnosis and management ${ }^{(4)}$.

Students in our were observed using apps more for education work and not for clinical reference as the cohort was of first and second year students only, however in other studies it was seen that Junior doctors refer to apps more for clinical scenarios and drug referencing. ${ }^{(4)}$ This should be kept in mind while developing apps in the future.
It was also seen that the students desire an app which would be developed in conjuction with the organization which would incorporate administrative information relating to timetabling and lecture content, also suggested were revision and quiz type apps ${ }^{(5)}$, Ho et al seen that students also wanted case logbooks on their $\operatorname{PDA}^{(6)}$. However no studies have explored the benefits of incorporating lecture timetabling and lecture objectives into a smartphone format. Payne et al noted that doctors are concerned more about information relating to patient management and care. $^{(4)}$

Smartphones have a few negative aspects also. Cost being the main concern among students and doctors ${ }^{(4)}$ Also with the changing trends it can be argued that with more usage cost benefit would translate to the users soon. Secondly cost of apps and uniformity of apps is a concern. A solution would be that organisations could bear the cost of recommended apps and also handsets for its employees. As our study data points to the majority of students were owning smart- phones, and with the expected fact that increase of smartphone usage is expected, the fact could be used to the advantage of the educational institute to encourage use of recommended free apps or developing an in house application for use.

\section{Conclusion}

Smartphones and mobile applications are ubiquitous and is an important part of our interconnected lifestyle. In a few years all medical students would beowningand using the same, hence use of medical apps for education and reference is bound to increase. A careful watch is required by medical educators regarding the quality and accuracy of medical apps. Hence increased interaction and awareness of medical apps among educators is the need of the hour.

\section{References}

1. Garritty C, El Emam K. Who's using PDAs? Estimates of PDA use by health care providers: a systematic review of 
surveys. Journal of medical Internet research. 2006;8.

2. Dasari KB, White SM, Pateman J. Survey of iPhone usage among anaesthetists in England. Anaesthesia. 2011;66(7):630-1.

3. Grasso MA, Yen MJ, Mintz ML. Survey of handheld computing among medical students. Computer methods and programs in biomedicine. 2006;82:196-202.

4. Payne KFB, Wharrad H, Watts K. Smartphone and medical related App use among medical students and junior doctors in the United Kingdom (UK): a regional survey. BMC medical informatics and decision making. 2012;12:121.

5. Torre DM, Treat R, Durning S, Elnicki M. Comparing PDA-and paper-based evaluation of the clinical skills of thirdyear students. WMJ. 2011;110:9-13.

6. Ho K, Lauscher HN, Broudo M, JarvisSelinger S, Fraser J, Hewes D, et al. The impact of a personal digital assistant (PDA) case log in a medical student clerkship. Teaching and learning in medicine. 2009;21:318-26. 